\title{
Energy tunnel linings thermo-mechanical performance: comparison between field observations and numerical modelling
}

\author{
Alessandra Insana ${ }^{1, *}$, Marco Barla $^{1}$, and Jean Sulem ${ }^{2}$ \\ ${ }^{1}$ Department of Structural, Building and Geotechnical Engineering, Politecnico di Torino, 10129 Torino, Italy \\ ${ }^{2}$ Laboratoire Navier, Ecole des Ponts Paris Tech, UGE, CNRS, 77455 Champs-sur-Marne, Marne-la-Vallée Cedex 2, France
}

\begin{abstract}
Energy linings are receiving great interest due to their potential to transform a tunnel into a smart energy system for enhancing thermal comfort of buildings and metro stations, as well as to absorb waste heat from the tunnel environment. Yet, besides their thermal performance, the impacts of equipping segments with a net of pipes are still challenging in the framework of energy tunnels structural design. Indeed, the thermal regime of the concrete members is altered due to heat carrier fluid circulation. Hence, the need to shed some light on the possible limit states attainment arises. In this paper, field monitoring of stresses and strains are presented for the first time in relation to a full scale monitored prototype of Enertun energy tunnel lining installed in Turin, Italy. Experimental data are compared to the results of a coupled thermo-mechanical numerical model, showing to be in good agreement. Criticalities from the ultimate limit state do not emerge, although a deeper analysis of serviceability limit states attainment should be performed.
\end{abstract}

\section{Introduction}

Heating and cooling in buildings and industry represents a major share of energy consumption. National strategies have been formulated in recent years to sharply cut the use of fossil fuels and to manage energy use by adopting more efficient technologies. Renewable energy-based systems have been increasingly promoted and put into practice for their ability to contribute to reduce carbon dioxide emissions, to diversify energy supply and to reduce dependence on oil and gas unreliable markets.

In the renewable energy sources framework, shallow geothermal energy represents one of the possible solutions that can be adopted to fulfil heating and cooling needs. In particular, both a geotechnical and an energy role can be played by structures in contact with the ground, such as piles, diaphragm walls, base slabs, anchors and tunnels, turning them into energy geostructures, by appropriately deploying plastic coils for heat exchange $[1,2]$. The possibility of thermally activating tunnels has been recently explored in different hydrogeological contexts, especially under the thermal performance point of view [3-6]. However, major concerns still exist on the consequences that the flow of a heat carrier fluid subject to progressive heating or progressive cooling depending on the operation mode could have on the concrete members structural performance. Very few studies in literature dealt with this peculiar aspect. Among them, [7] discussed the use of thermal tunnels with precast segments and the impact on structural performance with reference to the Crossrail project in London, where the need to cool the tunnel and the ground is crucial due to the noticeable heat generated by trains. By building a three-dimensional Finite Element (FE) Thermo-Mechanical (TM) model, they found that:

- under natural heating the average hoop stress through the segment thickness increases by about $7 \%$ in summer compared to the as-constructed case (about $0.28 \mathrm{MPa}$ ).

- when heating mode operation superimposes to natural summer temperatures the hoop stress increases by about $9 \%$ compared to the as-constructed case (about 0.36 $\mathrm{MPa})$.

- in winter negligible differences from the as-constructed case can be highlighted, both under natural conditions and with thermal activation of the geothermal plant.

- hoop stresses remain compressive at the extrados and intrados.

- local tensile stresses arise next to pipes, though remaining below the design tensile stress limit.

The mechanical effects were also investigated by [8] who built a coupled bi-dimensional TM model and assessed the stress state in the lining due to a one-year thermal activation summer-winter cycle. The thermallyinduced stresses, i.e. the stresses variations with respect to the as-constructed condition caused by the heat transfer process, were identified as being in the order of less than $1 \mathrm{MPa}$, with further compressions experienced by the lining during summer and decrease in compression during winter. No information on induced tunnel deformation was given. However, it appears that the range of stress variation is in line with the one suggested by [7] as well as [9] who investigated the effects related to anchors thermal activation on a bored

\footnotetext{
* Corresponding author: alessandra.insana@polito.it
} 
tunnel lining. According to the latter a maximum increase of up to $1.5 \mathrm{MPa}$ is reached during heat injection, while tunnel diameter variation is below $1 \mathrm{~mm}$. and slightly varies when considering silt or clay. These thermo-mechanical consequences are reputed relatively significant by [9], although [8] concludes that generally the design will not undergo substantial variations.

To systematically shed more light on the abovementioned aspects, an experimental and numerical study will be described in the present paper. First, the experimental campaign carried out, involving a full-scale prototype of energy tunnel lining Enertun-type [10], will be synthetized. Further details on the experimental site setup are outlined in [11]. Then two illustrative tests, one in heating mode and the other one in cooling mode will be discussed by presenting monitoring data pertaining to the lining stress-strain state. To the authors' best knowledge, thermo-mechanical experimental data for an energy tunnel do not exist in literature and hence can add a valuable piece to the puzzle of the understanding of energy tunnels thermo-mechanical behaviour. A numerical study is finally introduced and the methodology to simulate the two experimental tests is described. Comparison between monitoring and numerical outputs is carried out, by highlighting the variation in internal forces within the lining.

\section{Experimental campaign}

A full-scale prototype of energy tunnel comprising two rings was installed in 2017 in the tunnel under construction of Turin Metro line 1 South Extension in Italy, at a distance of about $42 \mathrm{~m}$ from the entrance of a station [11].

Turin subsoil is made of fluvioglacial deposits and presents an unconfined aquifer. In particular, in the location of the experimental site, the geological and geotechnical investigations allowed to define a stratigraphic profile mainly constituted by a sand and gravel unit, from loose to weakly cemented, apart from a shallow backfill layer. A West-to-East groundwater flow entirely intercepts the tunnel, whose axis is located at a depth of $16.6 \mathrm{~m}$, with a hydraulic gradient between 0.3 and $0.5 \%$. The phreatic surface can be found at a depth of about $12.4 \mathrm{~m}$.

Energy segments were precast in the prefabrication concrete plant and then mounted by the TBM itself on site. The Enertun configuration, including both ground and air circuit, was adopted and tested for the first time to assess its efficiency by performing a number of tests in heating and cooling mode in 2018 [12]. The two rings were connected in parallel to form the primary circuit, whereas a heat pump connected the primary circuit to the secondary one, represented by a fan coil unit. A comprehensive monitoring system was embedded within the precast reinforced concrete segments to investigate their thermo-mechanical behaviour. Indeed, one of the two rings was equipped with strain gauges provided with an embedded thermistor and pressure cells, all differently oriented, while in the second ring three pairs of Fiber Bragg Grating sensors were located. In the following the measurements obtained by the vibrating wire-based strain gauges and pressure cells will be considered, while a bespoke comparison among these and fiber optics-based sensors will be performed elsewhere. Fig. 1 depicts an as-built 3D view of the two rings with the monitoring sensors and the ground circuit (in blue). The details A-F show the orientation of the different sensors, reported also in Table 1 for the sake of clarity.
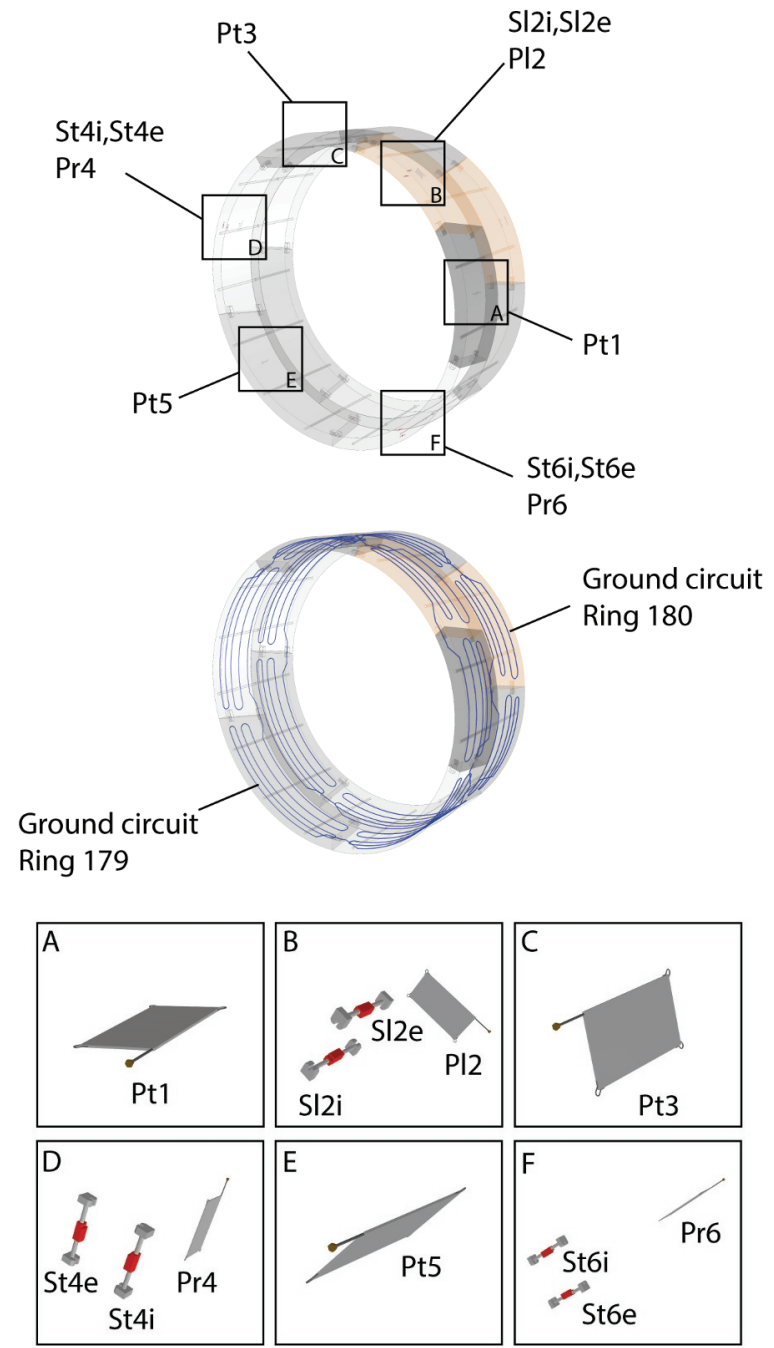

Fig. 1. 3D view of the experimental prototype with detail of pipes ground circuit and monitoring system $(\mathrm{S}=$ strain gauge, $\mathrm{P}=$ pressure cell, $\mathrm{t}=$ hoop direction, $\mathrm{r}=$ radial direction, $\mathrm{l}=$ longitudinal direction, $\mathrm{i}=$ intrados, $\mathrm{e}=$ extrados, $1-6=$ segment numbering from inlet to outlet). In orange is the key segment.

Table 1. Orientation and location of the monitoring sensors deployed in ring 179 of the experimental site.

\begin{tabular}{|c|c|c|}
\hline $\begin{array}{c}\text { Segment } \\
\text { number }\end{array}$ & $\begin{array}{c}\text { Vibrating-wire } \\
\text { strain gauge }\end{array}$ & Pressure cell \\
\hline 1 & - & $\mathrm{Pt} 1$ \\
\hline 2 & $\mathrm{~S} 2 \mathrm{i}, \mathrm{Sl} 2 \mathrm{e}$ & $\mathrm{Pl} 2$ \\
\hline 3 & - & $\mathrm{Pt} 3$ \\
\hline 4 & $\mathrm{St} 4 \mathrm{i}, \mathrm{St} 4 \mathrm{e}$ & $\mathrm{Pr} 4$ \\
\hline 5 & - & $\mathrm{Pt} 5$ \\
\hline 6 & $\mathrm{St6i}, \mathrm{St} 6 \mathrm{e}$ & $\mathrm{Pr} 6$ \\
\hline
\end{tabular}




\section{Description of a heating and a cooling test}

A 7.8-days heating test (about $48 \mathrm{~W} / \mathrm{m}^{2}$ of heat extracted from the ground) and a 3-days cooling test (about 60 $\mathrm{W} / \mathrm{m}^{2}$ of heat injected into the ground) among those performed are selected in the present work to show the comparison with the results of numerical modelling described in the following. Fig. 2 and Fig. 3 depict the monitoring data recorded for these two tests respectively. For example, for the heating test, fluid inlet and outlet temperatures (note that inlet and outlet refer to the rings) are shown, as well as the tunnel temperature measured by a probe fixed close to the rings' intrados (Fig. 2a). Also illustrated are the subsequent temperatures in the lining (Fig. 2b), thermally-induced strains (Fig. 2c) and thermally-induced stresses (Fig. 2d).

As well clarified in [13], a correction of the strain measurements was needed to take into account the effects of temperature on the deformation of the strain gauges steel wire. It is highlighted that positive strains indicate contraction, while positive stresses indicate an increase in compression.

It can be seen that during the heating test the heat carrier fluid circulation led to a variation of temperature in the lining of about $4-6^{\circ} \mathrm{C}$ and to a thermally-induced contractive hoop strain of about $50 \mu \varepsilon$. All pressure cells indicate a decrease in compression between 0.2 and 0.5 $\mathrm{MPa}$. Analogously, during the cooling test the opposite behaviour is shown. For an increase in temperature of 5 $7^{\circ} \mathrm{C}$ expansive strains are shown, in the order of about 60 $\mu \varepsilon$, despite the stress behaviour is not mirrored. Indeed, higher variations in stresses arise and it appears that a decrease in compression by 2.5-4 MPa is induced.

\section{Numerical modelling}

To better understand the thermo-mechanical phenomena occurring during the hydraulic flow and heat transfer process, a 2D coupled thermo-mechanical, finitedifference numerical model was built. In the following the methodology adopted is described, together with the analysis details and the results obtained.

\subsection{Methodology}

First a 3D coupled thermo-hydraulic (TH), model was built, calibrated and validated [12] using the Finite Element software Feflow [14]. Then, the tests presented in this paper were simulated by imposing inlet temperature, tunnel temperature and fluid velocity equal to the measured ones (again see [12] for further details). The resulting temperature field obtained in correspondence of the cross sections where gauges are located (Fig. 4) was exported to a GIS (Geographic Information System) software. Hence, temperatures could be evaluated at the nodes of the TH model mesh. However, this discretization grid was different from the TM model one (Fig. 5) and an intermediate interpolation step was performed with the aim to get a continuous temperature field. This step was followed by the extrapolation of raster temperature values to the nodes of the TM model according to the shape given by the imported TM grid (nodes coordinates $x, y$ ). This process was repeated for both tests and both sections where stress and strain gauges are placed, at mid-thickness and at a longitudinal distance of $15 \mathrm{~cm}$ from the adjacent non-energy ring respectively. The nodal temperatures were then imported in the TM model at the end of the mechanical-only simulation of the excavation process by means of a user-defined function written in the FISH language.
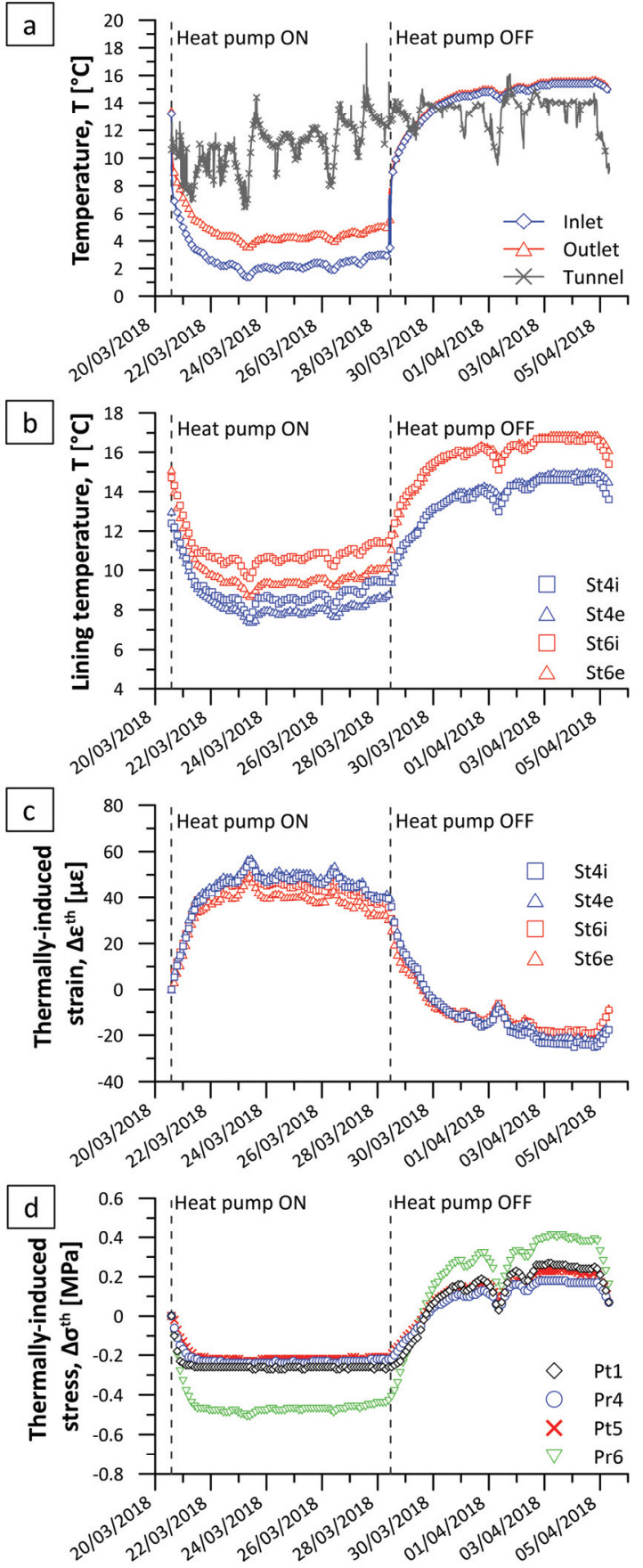

Fig. 2. (a) Heating test with corresponding (b) lining temperature, (c) thermally-induced strains and (d) thermallyinduced stresses. 


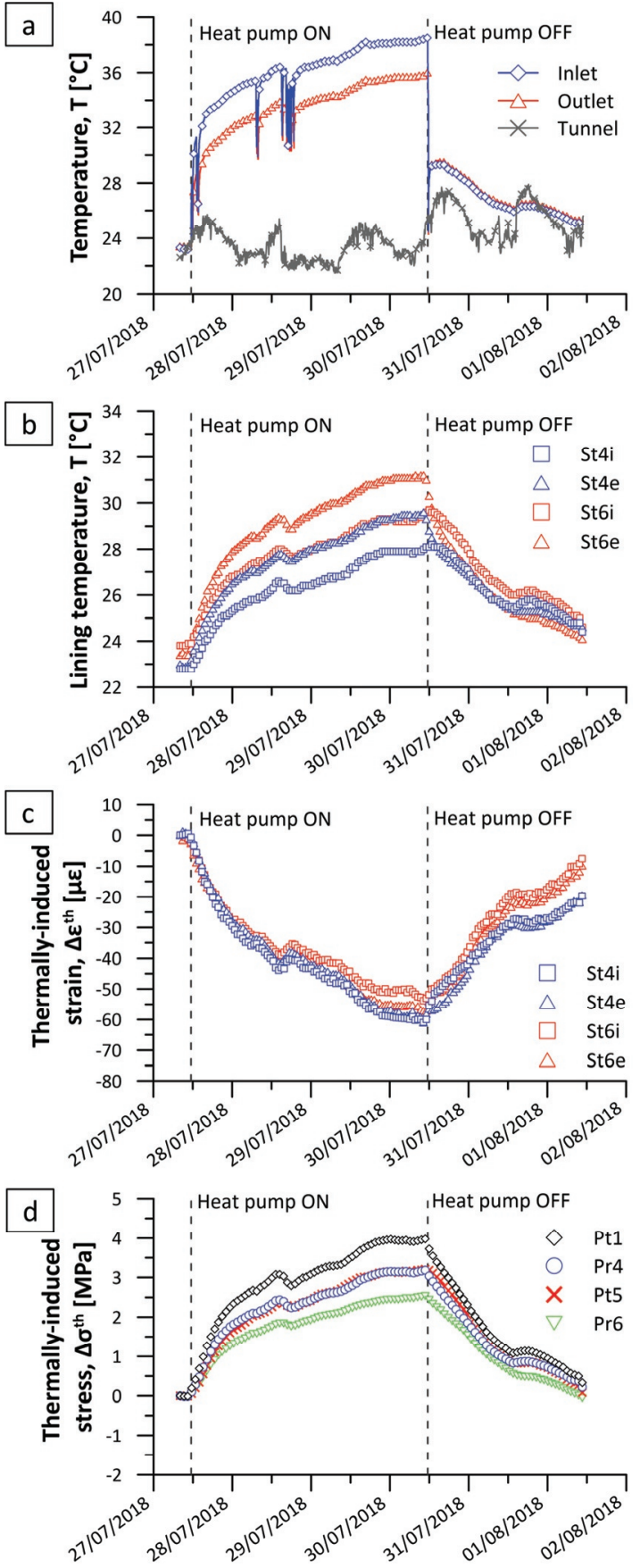

Fig. 3. (a) Cooling test with corresponding (b) lining temperature, (c) thermally-induced strains and (d) thermallyinduced stresses.

\subsection{Modelling procedure and input parameters}

The finite-difference (FD) grid built in FLAC [15] shown in Fig. 5 and consisting of 32268 elements is $74.8 \mathrm{~m}$ high and $149.6 \mathrm{~m}$ wide. The boundaries are positioned at a distance such as to minimize constraints influence on the area of interest. Horizontal displacements are prevented laterally, while vertical displacements are blocked on the lower side. As mentioned, the tunnel axis is $16.6 \mathrm{~m}$ deep and the tunnel diameter is $7.48 \mathrm{~m}$. The model emulates the hydrogeological conditions existing in situ, characterized by a $2 \mathrm{~m}$-thick backfill layer, above a sand and gravel unit (so-called Geotechnical Unit 2 or GU2, according to [16]). After reproducing the geostatic conditions, a drained, time-independent analysis was performed to simulate tunnel construction using the convergenceconfinement method [17]. The mechanical properties adopted for the different materials involved are listed in Table 2 (these values are inferred both from [16] and from the final design report). A simple elastic model was used for concrete lining and grout injection, while an elastic-perfectly plastic Mohr-Coulomb model for the backfill and GU2.
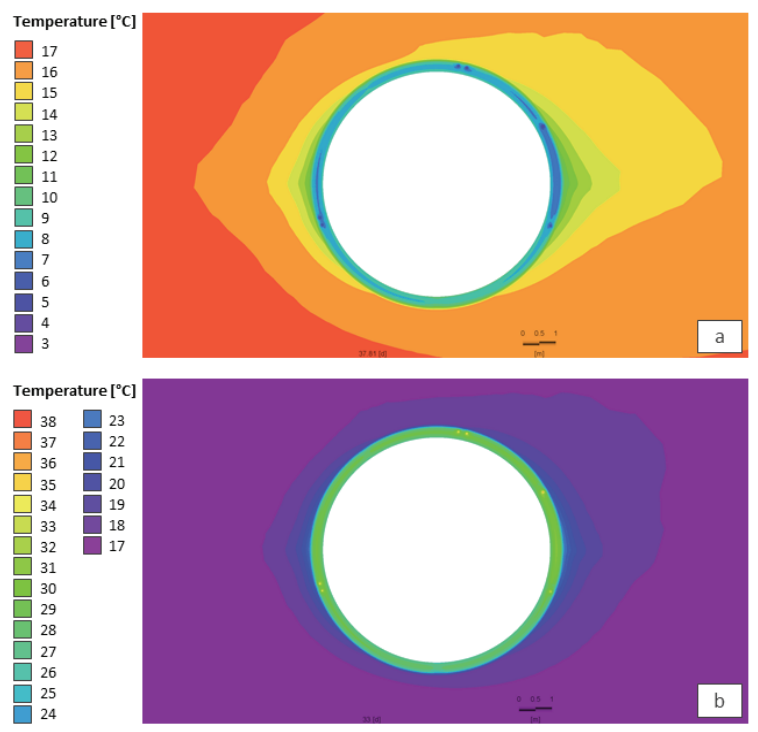

Fig. 4. Temperature field obtained from the 3D TH finite element model at the end of the (a) heating and (b) cooling tests within the cross section where pressure cells are located.

The calculation stages are recalled hereafter:

- Initialization of stresses with the groundwater table at a depth of $12.4 \mathrm{~m}$ and surface loads.

- Excavation simulation by deleting the elements within the excavation boundary and applying a gradually decreasing internal pressure until $20 \%$.

- Activation of the fresh grout and lining elements, and further $10 \%$ stress release.

- Change of grout properties to its hardened state and complete stress release.

- Definition of thermal properties (Table 2, where heat capacity and thermal conductivity match those assigned in the TH model), assignment of initial temperatures and uncoupled thermo-mechanical simulation (nothing occurs in this stage, which is useful to define the starting thermal point).

- Reset of displacements, assignment of temperatures corresponding to the end of the tests and uncoupled thermo-mechanical simulation to assess the variation in the stress-strain state.

At the end of the excavation the radial stresses range between -0.08 and $0.08 \mathrm{MPa}$, whereas the hoop stresses between -0.4 and $1.4 \mathrm{MPa}$ (the crown intrados results slightly in tension). 

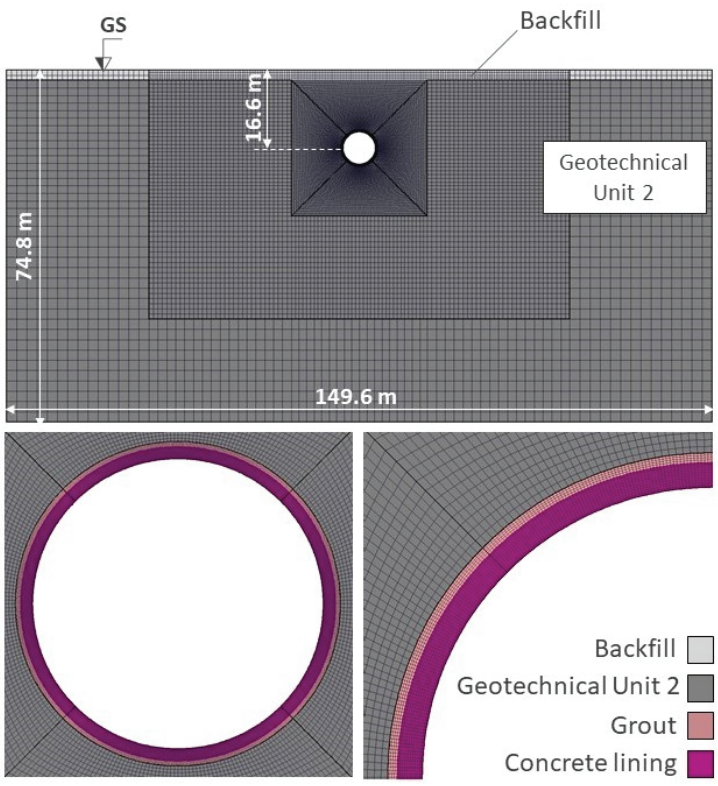

Fig. 5. Finite difference mesh of the thermo-mechanical numerical model with stratigraphy.

Table 2. Mechanical and thermal model properties.

\begin{tabular}{|c|c|c|c|c|}
\hline Property & Backfill & GU2 & Grout & Lining \\
\hline$\gamma\left[\mathrm{kN} / \mathrm{m}^{3}\right]$ & 15.5 & 17 & 18.5 & 25 \\
\hline $\mathrm{E}_{\mathrm{y}}[\mathrm{MPa}]$ & 15 & $190-240$ & $5-5000$ & 35200 \\
\hline$v[-]$ & 0.35 & 0.3 & 0.25 & 0.2 \\
\hline$\varphi^{\prime}\left[{ }^{\circ}\right]$ & 36.5 & 38 & - & - \\
\hline$c^{\prime}[\mathrm{kPa}]$ & 1 & 30 & - & - \\
\hline$\sigma_{\mathrm{t}}[\mathrm{kPa}]$ & 1 & 15 & - & - \\
\hline$\lambda[\mathrm{W} /(\mathrm{mK})]$ & 2.26 & 2.26 & 0.655 & 1.12 \\
\hline$\left.c_{\mathrm{p}}[\mathrm{J} / \mathrm{kgK})\right]$ & 1209 & 1209 & 1184 & 876 \\
\hline$\alpha_{\text {th }}[1 / \mathrm{K}]$ & $1 \cdot 10^{-5}$ & $1 \cdot 10^{-5}$ & $1 \cdot 10^{-5}$ & $1 \cdot 10^{-5}$ \\
\hline
\end{tabular}

\subsection{Numerical results}

The thermally-induced radial and hoop stresses and the thermally-induced hoop strains at the end of the simulation of the heating and cooling tests are shown in Fig. 6 and Fig. 7 respectively. The sign convention is the same as the one for experimental results. As it can be seen, no relevant variation in radial stress occurs $(<0.08$ $\mathrm{MPa}$ ) neither for heating (Fig. 7a) nor cooling (Fig. 7b), which is different from what was observed experimentally. This could be due to different thermal expansion coefficients of the grout and the concrete lining. Hoop stresses at mid-thickness are compatible in the numerical simulations and in the experiments and indicate a decrease in compression for the heating test (between -0.14 and $-0.38 \mathrm{MPa}$ in the numerical simulation and between -0.21 and $-0.26 \mathrm{MPa}$ in the experiment) and an increase in compression for the cooling test (between 0.4 and $0.58 \mathrm{MPa}$ in the numerical simulation, but between 3.1 and $3.6 \mathrm{MPa}$ in the experiment). The mismatch in cooling mode could be due to the simplified assumption of monolithic lining, that does not take into account the segmental nature of the energy ring. The direction and amount of strains variation is also consistent, as extension is obtained upon cooling and contraction upon heating both at the extrados and at the intrados, as in Fig. 2c and Fig. 3c.

Based on these results internal forces acting on the lining were calculated and compared to the as-constructed case (Fig. 8). The combinations of axial force and bending moment N-M corresponding to maximum axial force, maximum bending moment and minimum bending moment were computed and represented together with the strength envelope of the representative cross section of the lining. It was found that these forces are largely included in the envelope, thus showing the little influence of thermal activation on the ultimate limit state of the lining.

Moreover, it can be observed that the order of magnitude of stresses and strains variations does not exceed the one due to natural temperature variations and presented in [11]. Hence, although thermally-induced effects are not negligible, they are not considered to threaten the structural integrity of the lining. Further verifications are needed to verify the lining with respect to the serviceability limit state of stress limitation and cracking control.

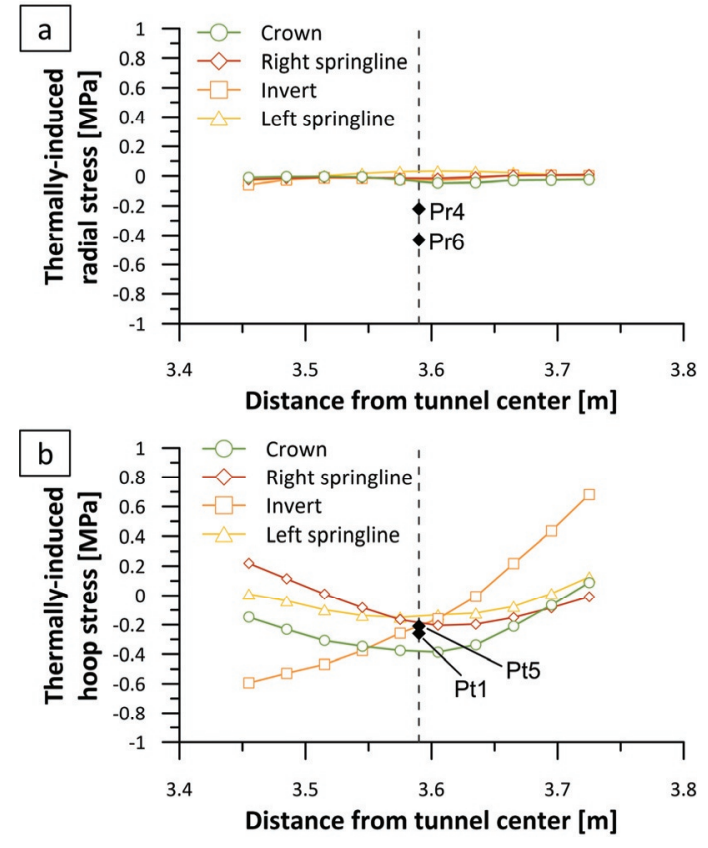

Fig. 6. Numerical results in terms of thermally induced (a) radial stresses and (b) hoop stresses across the lining thickness at the end of the heating test. In black are experimental results.

\section{Conclusions}

This study focussed on the thermo-mechanical behaviour of energy linings, which is still little studied and deserves a special attention to boost the uptake of energy tunnels around the world. The methods employed included (i) full-scale in situ testing and (ii) numerical modelling. The experimental activity presented the evidences of the thermally induced stress-strain performance of such structures. The TM numerical analyses aimed at providing a fundamental 
characterisation of the response of energy tunnels to thermal and mechanical loads. The results illustrated allowed concluding that thermal loads acting on tunnels in alluvial soils involve effects that can be neglected in performance-based design of the lining at ultimate limit state. Indeed, little variations in internal forces were detected in comparison to the as-constructed condition. However, the effects of thermal loads still need to be investigated at the serviceability limit state.

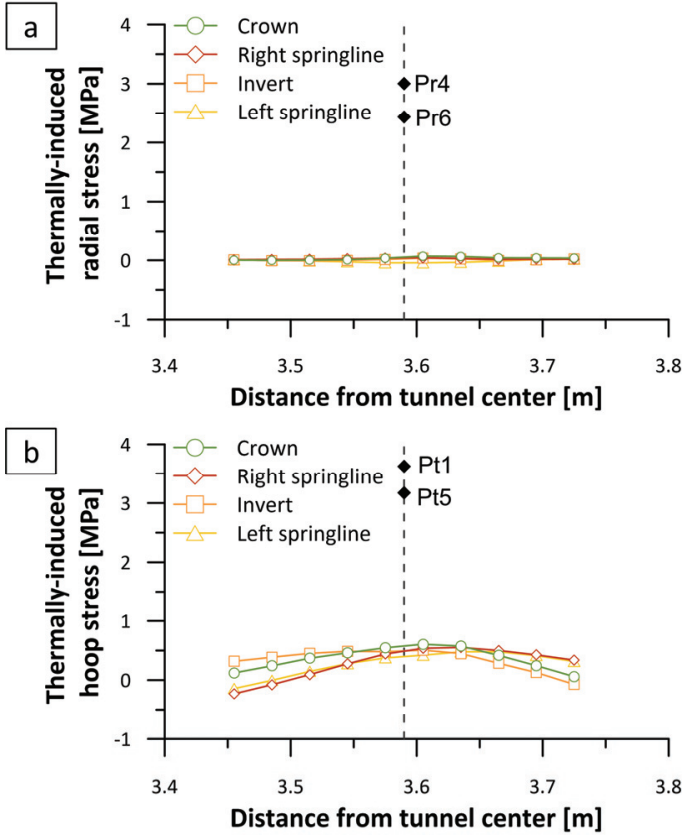

Fig. 7. Numerical results in terms of thermally induced (a) radial stresses and (b) hoop stresses across the lining thickness at the end of the cooling test. In black are experimental results.

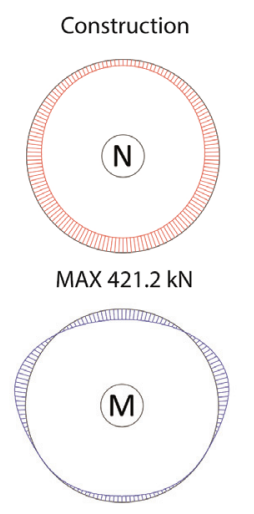

MIN $-22.8 \mathrm{kNm}$ MAX 19.2 kNm

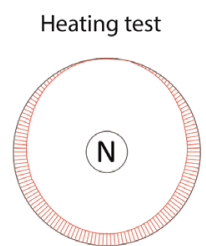

MAX $407.0 \mathrm{kN}$

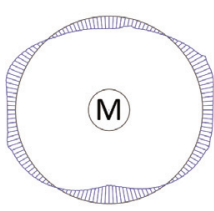

MIN $-30.5 \mathrm{kNm}$ MAX $33.9 \mathrm{kNm}$

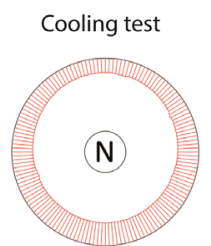

MAX $638.2 \mathrm{kN}$

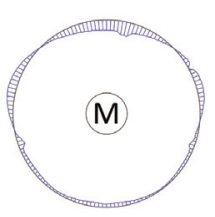

MIN $-15.3 \mathrm{kNm}$ MAX $26.6 \mathrm{kNm}$
Fig. 8. Computed axial force and bending moment along the tunnel lining at the end of construction, of the heating test and of the cooling test.

\section{References}

1. L. Laloui, A. Di Donna, Energy Geostructures: Innovation in Underground Engineering. ISTE Ltd and John Wiley Sons Inc. (2013)
2. K. Soga, Y. Rui, Energy geostructures, in: S.J. Rees (Ed.), Advances in Ground-Source Heat Pump Systems, Woodhead Publishing, 185-221 (2016)

3. A. Di Donna, M. Barla, The role of ground conditions and properties on the efficiency of energy tunnels, Environ. Geotech. 3(4), 214-224 (2016)

4. M. Baralis, M. Barla, W. Bogusz, A. Di Donna, G. Ryzynski, M. Zerun, Geothermal potential of the NE extension Warsaw metro tunnels, Environ. Geotech., 1-13 (2018)

5. M. Barla, M. Baralis, A. Insana, F. Zacco, S. Aiassa, F. Antolini, F. Azzarone, P. Marchetti, Feasibility study for the thermal activation of Turin Metro Line 2, in: Proceedings of the WTC 2019 ITA-AITES World Tunnel Congress, CRC Press/Balkema, 231240 (2019)

6. J. Epting, M. Baralis, R. Künze, M.H. Mueller, A. Insana, M. Barla, P. Huggenberger, Geothermal potential of tunnel infrastructures e development of tools at the city-scale of Basel, Switzerland, Geothermics 83 (2020)

7. D.P. Nicholson, Q. Chen, M. de Silva, A. Winter, R. Winterling, The design of thermal tunnel energy segments for Crossrail, UK, Eng. Sustain., 167, ES3, 118-134 (2014)

8. M. Barla, A. Di Donna, Energy tunnels: concept and design aspects, Underg. Sp., 3, 4, 268-276 (2018)

9. T. Mimouni, Thermomechanical characterization of energy geostructures with emphasis on energy piles, $\mathrm{PhD}$ thesis, EPFL, Lausanne, Switzerland (2014)

10. M. Barla, A., Di Donna, Conci energetici per il rivestimento delle gallerie, Strade \& Autostrade, 5 (2016)

11. M. Barla, A. Di Donna, A. Insana, A novel realscale experimental prototype of energy tunnel, Tunn. Undergr. Sp. Tech., 87, 1-14 (2019)

12. A. Insana, M. Barla, Experimental and numerical investigations on the energy performance of a thermo-active tunnel, Ren. Energy 152, 781-792 2020)

13. T. Mimouni, L. Laloui, Full-scale in situ testing of energy piles. In Energy Geostructures: Innovation in Underground Engineering (L. Laloui, A. Di Donna (eds)). ISTE, London, UK and Wiley, Hoboken, NJ, USA, 23-43 (2013)

14. H.J.G. Diersch, DHI Wasy Software - Feflow 6.1 Finite Element Subsurface Flow \& Transport Simulation System: Reference Manual (2009)

15. Itasca, FLAC ver.7.0 user's manual (2016)

16. M. Barla, G. Barla, Turin subsoil characterization by combining site investigations and numerical modelling, Geomechanics and Tunnelling, 5, No. 3, 214-231 (2012)

17. M. Panet, Le calcul des tunnels par la méthode convergence-confinement, Paris, Presses de l'Ecole Nationale des Ponts et Chaussées (1995) 